\title{
"Anti-COVID-19" Medications, Supplements, and Mental Health Status in Indonesian Mothers with School-Age Children
}

\author{
Annette d'Arqom (iD) 1,2 \\ Brihastami Sawitri (iD) 2,3 \\ Zamal Nasution iD ${ }^{4}$ \\ Riko Lazuardi ${ }^{5}$ \\ 'Division of Pharmacology, Department of \\ Anatomy, Histology, and Pharmacology, \\ Faculty of Medicine, Universitas Airlangga, \\ Surabaya, Indonesia; ${ }^{2}$ Translational \\ Medicine and Therapeutic Research Group, \\ Universitas Airlangga, Surabaya, Indonesia; \\ ${ }^{3}$ Department of Psychiatry, Faculty of \\ Medicine, Universitas Airlangga, Surabaya, \\ Indonesia; ${ }^{4}$ Institute for Population and \\ Social Research, Mahidol University, \\ Bangkok, Thailand; ${ }^{5}$ District Level Health \\ Office, Surabaya, Indonesia
}

Purpose: The COVID-19 pandemic affects all aspects of life and might cause stress for vulnerable groups such as mothers with school-age children, both housewives and working mothers. With the uncontrolled circulating information about medications, supplements, and herbs that are believed to treat COVID-19, self-medication and misused might escalate. Therefore, this study aims to determine the consumption of "anti-COVID" agents and the mental health of mothers with school-age children in Indonesia.

Methods: Online questionnaires regarding medications/supplements for COVID-19 prevention and treatment of "anti-COVID" consumption behavior and mental health using the Depression, Anxiety, and Stress Scales (DASS-21) were distributed among Indonesian mothers with school-age children. Data $(n=610)$ were analyzed; descriptive and association between sociodemographic factors, "anti-COVID" medications consumption, and mental health were presented.

Results: A quarter of the respondents were categorized as having mental disorders, with higher scores of DASS-21 was higher in the housewives' group. The incidence associated with age, family expenses, and marital status in the working mothers' group, and only with family expense in the housewives' group. Moreover, the result showed $80 \%$ of the respondents consumed "anti-COVID" medications or supplements to prevent COVID-19, with 75\% did self-medication without consulting with a healthcare professional. Friends/family and social media were two primary sources of information regarding the "anti-COVID" products. In the housewives' group, their consumption behavior was influenced by education. Meanwhile in the working mothers' group, the consumption behavior was influenced by age, family income, and family expense. In addition, there was no association between the usage of medications/supplements with the respondents' mental health status.

Conclusion: This study showed the importance of controlling information and expanding the mother's knowledge to find the correct information to minimize the unwanted effect in the post COVID-19 pandemic. Increasing awareness of mental health issues in the community, especially in the vulnerable population such as mother with school-age children, is necessary to avoid detrimental effects that might occur in the future.

Keywords: mental health, natural product, self-medication, vitamin

\section{Introduction}

Correspondence: Annette d'Arqom Division of Pharmacology, Department of Anatomy, Histology, and Pharmacology, Faculty of Medicine, Universitas Airlangga, Jl. Mayjen Prof. Dr. Moestopo 47, Surabaya, 60I3I, East Java, Indonesia Email annette-d-a@fk.unair.ac.id
COVID-19 is caused by SARS-CoV-2, which is easily transmitted through droplets and can survive for some time on surfaces. Because the virus spreads quickly, maintaining physical distance, individual hygiene, and wearing a mask are essential for prevention. ${ }^{1}$ Many countries imposed lockdowns that prevented people from 
entering and leaving countries and limited residents' activities, reducing the incidence of COVID-19. ${ }^{2,3}$ Mass contact tracing also effectively reduced the spread. ${ }^{4,5}$ Unfortunately, some countries still have difficulties in combating this disease, including Indonesia. ${ }^{6,7}$

In Indonesia, physical distancing started in the middle of March 2020, about 2 weeks from the announcement of the first case in Jakarta, followed by large-scale social restrictions at the end of March 2020 that included the closing of schools and offices, restrictions on religious activities, and bans on activities in public places. ${ }^{8}$ This situation was very likely to be stressful for some individuals; fear and anxiety about an illness can be overwhelming. Changes in activity patterns and withdrawal of physical activity led to some confusion, including among mothers. ${ }^{9,10}$ In the population of mothers, increased responsibilities included teaching the children, performing household chores, and engaging in work tasks. The reduced outdoor activities in children forced mothers to spend more time with their children. ${ }^{11}$ In this scenario, conflict is inevitable because these interactions are intense and endless. In China, the first country to lockdown, the divorce rate increased, and domestic violence was reported more frequently. ${ }^{12-14}$ Even worse, decreased income, increased consumption, and rising prices for staple foods contributed to the burden. ${ }^{15}$ Taken together, all these factors might affect mental health status. $^{16}$

Reaction to stressful situations is affected by demographic background. During this pandemic, people worry about personal and family health which might changes in sleeping or eating patterns, worse chronic health problems, or excessive intake of alcohol, tobacco, medications, and supplements. ${ }^{17}$ Information about medications and supplements as COVID-19 therapies or preventions ("antiCOVID") are widely circulated, which leads to selfmedication practice. ${ }^{18,19}$ Before pandemic, selfmedication practice has been common in Indonesia, ${ }^{20}$ including consumption of natural products in Indonesian mother ${ }^{21}$ and over the counter (OTC) drugs in Indonesian pregnant women. $^{22}$

In 2013, it was reported that the prevalence of mental health disorders, including emotional and mood disorders in Indonesia, was $6 \%$ or 14 million people. Unfortunately, only $10 \%$ had access to health facilities, ${ }^{23}$ with suicide mortality rate was 3.4 of 100,000 population. ${ }^{24}$ During the COVID-19 pandemic, it was reported that females more likely to experience medium to high anxiety, as well as working respondents (male and female) compared to housewives. ${ }^{25}$ While during non-pandemic, it was reported that working mothers had better health, less depressive symptoms, and higher self-esteem compared to housewives. $^{26,27}$

Taken together, with the amount of pressure endured by mothers with school-age children, mental disorders are likely to occur, as well as increasing consumption of "antiCOVID" medications and supplementations. Therefore, this study aimed to explore the mental health of mothers with school-age children, in working mothers and housewives, during the COVID-19 pandemic. Its relationship with the consumption of "anti-COVID" medications and supplements was further investigated.

\section{Materials and Methods Study Design and Data Collection}

This cross-sectional study regarding the association between consumption of "anti-COVID" medications, vitamin and mineral supplementation, herbs or natural product supplementation and the mental health status of Indonesian mothers with school-age children during the COVID-19 pandemic was conducted in JulyDecember 2020. The study protocol has been approved by the Health Research Ethics Committee, Faculty of Medicine Universitas Airlangga (No. 180/EC/KEPK/ FKUA/2020). All methods were conducted in accordance with the Declaration of Helsinki. Respondents were provided with an explanation of the objectives and consents of the questionnaire, which included a clause of publicity on the anonymous responses, at the beginning of the survey. Moreover, respondents were required to click BEGIN button as a sign of consent before they proceeded to start the survey.

The primary data were collected from the online questionnaire (www.surveyplanet.com) distributed by trained surveyors face-to-face and through social media such as WhatsApp, Facebook, and emails using a convenience sampling method. The online questionnaire was set to prevent multiple submissions from one device. Moreover, to reach wider respondents, specially-trained research staff recruited respondents in several cities of Indonesia, and guided the respondent to access the online questionnaire, and the respondent further completed and submitted the questionnaire independently. This study followed the Checklist for Reporting Results of Internet E-Surveys (CHERRIES) guidelines. ${ }^{28}$ 
Respondents were Indonesian mothers with school-age children (elementary-high school students), older than 18 years old, and domiciled in Indonesia during the COVID19 pandemic. We excluded those who were not Indonesian women, without school-age children, younger than 18 years old, or domiciled outside Indonesia during the COVID-19 pandemic. The required minimum sample size was 383 respondents, calculated using a sample size calculator (www.surveymonkey.com) with 5\% margin of error, 95\% confidence level, and unknown population number (filled with 100,000). Furthermore, to explore their feelings and medications/supplements consumption behavior, eighteen respondents were contacted and in-depth interviews were performed by RL by phone. The selection was based on the respondent's DASS score and their "anti-COVID” drugs and supplements consumption behavior.

\section{Survey Instrument}

A set of questionnaires of three sections was distributed to measure respondents' medications or supplementation and their mental health. The sections consisted of the basic demographic information, consumption of "anti-COVID" medications and supplements, and measurement of mental health using the Depression, Anxiety, and Stress Scales 21 (DASS-21). Two native Indonesians translated DASS$21 .^{29}$ The Indonesian version of the DASS-21 was evaluated by two experts, a psychiatrist and social science expert, to determine its suitability for being adapted into local conditions. Likewise, a section of medications and supplements behavior was developed by a pharmacologist and evaluated by two experts, a pharmacologist and a medical doctor. Furthermore, the questionnaire was tested in 20 Indonesian mothers with school-age children to assure their understanding. After completing the form, respondents were asked to evaluate their understanding of the questions, including the wording and the format.

\section{Analytical Procedure}

Respondents were divided into two groups based on their activities, housewives or working mothers. Medications and supplements consumption behaviors were measured using nominal or ordinal scales. The respondents' locations were derived from the survey record. The answers to the DASS-21 were calculated according to the guidelines. Total scores were obtained and divided into five groups for each category (depression, anxiety, and stress): normal, mild, moderate, severe, and extremely severe. Data were managed in Microsoft Excel, analyzed using SPSS 25.0 (IBM, Chicago,
IL), and graphs were drawn using GraphPad Prism 5.0. Descriptive statistical analyses were performed, and response rates were calculated as percentages on every item related to categorical variables. The differences of sociodemographic factors between two groups were calculated using chi-square test. The Mann-Whitney U and Kruskal-Wallis $H$-test were used to measure the sociodemographic factors influencing the respondents" "anti-COVID" consumption behavior and mental health status, whilst the association between "antiCOVID" consumption and mental health status was measured using Fisher's Exact Test. Significance was defined as a $p$-value $<0.05$. The reliability measurement on the survey data showed a Cronbach Alpha value 0.786 for depression, 0.727 for anxiety, and 0.811 for stress with nonnormality data distribution.

\section{Results}

\section{Characteristics of Respondents}

Nine hundred nineteen respondents visit the informed consent page, 610 complete questionnaires were received and valid for use in the final analysis; the completion rate was $66.38 \%$. Two hundred twenty respondents self-described as housewives (36\%), and 390 respondents self-described as working mothers (64\%). As recorded by the survey online tools, most of the respondents were located on Java Island, the most developed island in Indonesia. The respondents' ages varied from 18 to $>50$ years old, with most of the respondents were at $31-40$ years in both groups. Nearly all respondents in both groups were married, with higher numbers or unmarried or divorced or widower in the working mothers; than the housewives ( $6.2 \%$ vs $2.8 \%$, respectively). Educational background, family income, and family expenses between the two groups showed significant differences. Even though most of the respondents in both groups held bachelor's degrees for educational background, there were disparities between the two groups with more housewives held high school degrees and fewer graduate degrees $(p<0.000)$. Moreover, self-reported family income and family expenses were higher in working mothers compared to the housewives ( $p<0.000$ and $p<0.001$, respectively). All respondent demographic factors are displayed in Table 1.

\section{Mental Health Status of Mothers with Schol-Age Children and Its Association with Sociodemographic Factors}

Using the DASS 21 questionnaire (Table S1), the trends of mothers with school-age children were calculated and 
Table I Characteristics of Respondents $(N=610)$

\begin{tabular}{|c|c|c|c|c|}
\hline Characteristic & Housewives $(\mathbf{N}=220) \mathbf{N}[\%]$ & Working Mothers $(\mathrm{N}=390) \mathrm{N}$ [\%] & $\mathbf{x}^{2}$ & $P$ value \\
\hline Age & & & 11.43 & 0.01 \\
\hline $18-30 y$ & $20[9.1]$ & $17[4.4]$ & & \\
\hline $31-40 y$ & $133[60.5]$ & $209[53.6]$ & & \\
\hline $4 I-50 y$ & $61[27.7]$ & $15 \mid[38.7]$ & & \\
\hline$>50 y$ & $6[2.7]$ & $13[3.3]$ & & \\
\hline Location & & & 4.0 & 0.046 \\
\hline Java Island & $202[91.8]$ & $337[86.4]$ & & \\
\hline Other Islands & $18[8.2]$ & $53[13.6]$ & & \\
\hline Marital & & & 3.53 & 0.06 \\
\hline Married & $214[97.3]$ & $366[93.8]$ & & \\
\hline Unmarried/Divorce/Widow & $6[2.7]$ & $24[6.2]$ & & \\
\hline Education & & & 113.57 & 0.000 \\
\hline Lower than Senior High School & $12[5.4]$ & $3[0.8]$ & & \\
\hline Senior High School & 7I [32.3] & $33[8.5]$ & & \\
\hline Bachelor & $123[55.9]$ & 204 [52.3] & & \\
\hline Graduate degree & $14[6.4]$ & $150[38.4]$ & & \\
\hline Family Income (in USD) & & & 104.2 & 0.000 \\
\hline$<69$ & 74 [33.6] & 19 [4.9] & & \\
\hline $69-345$ & $90[40.9]$ & 159 [40.8] & & \\
\hline $346-690$ & $30[13.7]$ & $133[34.1]$ & & \\
\hline$>690$ & $26[11.8]$ & $79[20.2]$ & & \\
\hline Family Expenses & & & 14.954 & 0.001 \\
\hline More than income & 73 [33.2] & 75 [19.2] & & \\
\hline Similar with income & $102[46.4]$ & $215[55.1]$ & & \\
\hline Less than income & $45[20.4]$ & $100[25.7]$ & & \\
\hline
\end{tabular}

Note: Boldface p-values indicate significant differences between groups based on chi-square test.

analyzed. Our study found that $21 \%$ of the respondents had depression, $25.7 \%$ had anxiety, and $8.2 \%$ categorized as stress. Even though we hypothesized that the incidence of mental disorders would be elevated in working mothers, our findings showed contrary results, the results showed higher scores of depression, anxiety, and stress in the housewives than the working mothers during the pandemic $(p<0.01, p<0.01$, and $p<0.001$, respectively, Figure 1A). Similar result was found when it was categorized into each mental health disorder, though only depression was a statistically significant difference between these two groups $(p=0.044)$. (Table S2).

The symptoms of mental health reported by respondents included insomnia, dyspnea, hyperventilation, inability to focus, anger, and suicidal thought. However, during the in-depth interviews, respondents felt these problems did not lead them to have problems with others. Their family and friends understood their problems, and they felt grateful for this, even though they felt worse when they showed their anger in front of their families.

To determine the sociodemographic factors that were associated with mental health, data from each group were analyzed. The results showed various sociodemographic factors associated with the mental health disorders in each group and category. In the housewives' group, the family expense was the only significant influencer to the incidence of anxiety. In contrast, in the working mother group, age and family expenses influenced the incidence of depression, anxiety, and stress; whilst marital status might affect the anxiety incidence (Figure $1 \mathrm{~B}$ and Table S3).

The age of the respondents contributed to the incidence of the three mental health disorders in working mothers. We found mothers older than 50 years with school-age children, followed by the youngest mother groups in this study (18-30 years old), more likely to have mental health 


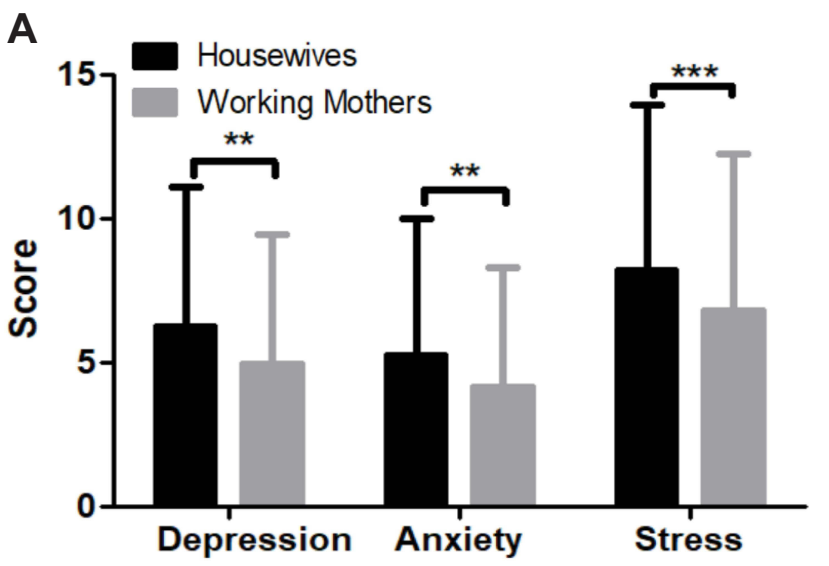

B

Age

Location

Marital

Education

Family Income

Family Expense
Housewives

Working

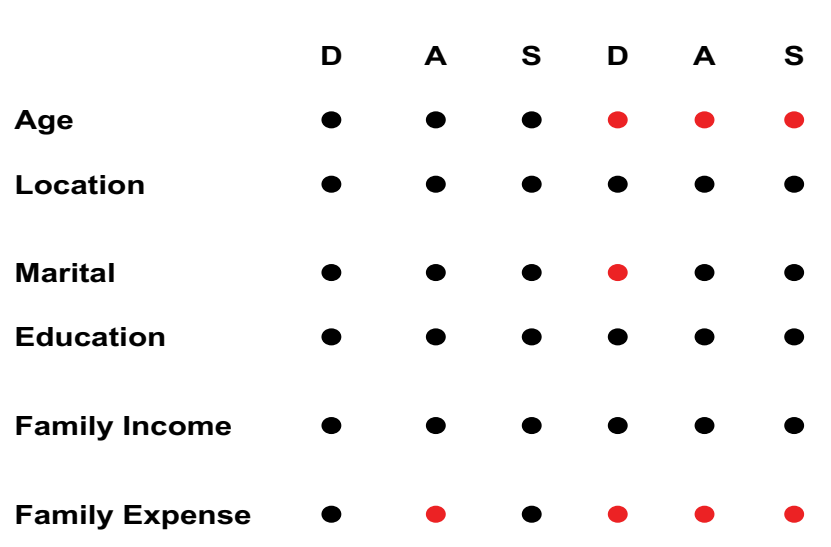

Figure I DASS-2I in housewives and working mothers. (A) A total score of DASS $2 I$ in housewives and working mothers. Mann-Whitney U-test was performed, the results showed mean $\pm \mathrm{SD}$. $* * \mathrm{P}<0.01$, $* * * \mathrm{P}<0.001$. (B) Influences of sociodemographic factors on the mental health of housewives and working mothers. Sociodemographic factors significantly $(\bullet)$ and non-significantly $(\bullet)$ influenced respondents' mental health: depression (D), anxiety $(A)$, and stress $(S)$ analyzed by Kruskal Wallis Test. A complete statistical analysis was provided in Table S3.

disorders compared to middle age mothers (31-50 years old). The trend toward three mental health disorders was more likely in mothers with living expenses higher than income, followed by mothers with life expenses lower than income; and the less likely to have mental disorders was the group with balanced life expenses and income (15.1\%) (Table S5 I1-2). Another factor that might contribute to the incidence of anxiety was marital status, where the DASS-21 score of unmarried/widower/divorce mother was significantly higher compared to the married mother.

Moreover, since children's education was affected during this pandemic. Our qualitative study found that switching from face-to-face learning to internet-based learning might introduce new burdens on a mother or even became a blessing in disguise to build a better parent-children bond. The burden of online learning, mainly because there were new responsibilities while the previous responsibilities were not reduced. They also felt relieved when someone could guide or take care of their school-age children during the pandemic (Table S5 I3-4).

\section{Consumption of "Anti-COVID" Medications, Vitamin, and Herbal Supplements and Its Association with Sociodemographic Factors}

Using ordinal scales 1 for not consumed, 2 for not routinely consumed, and 3 routinely consumed, the findings showed that housewives consumed more herbs/natural products than working mothers $(2.21 \pm 0.74$ vs $1.8 \pm$ 0.72 , respectively, $p=0.000$ ), and there was no significant difference between housewives and working mothers for medications and vitamins and minerals supplementation consumption (Table 2). The most common medications that were consumed including antibiotics ( $42 \%)$ and symptomatic medications (37\%) such as antipyretics, cold medications, antihypertension, and blood glucose-lowering agents. While in the supplements groups, antioxidant vitamins and minerals that important for the immune system, such as vitamin C (39\%), were widely consumed by the respondents. The herbs or natural products most frequently taken during this pandemic for instance ginger (31\%) and honey $(30 \%)$ which popular for their anti-inflammatory properties. Figure S1 summarized the "anti-COVID" medications and supplementations consumed by the respondents.

The main reason for consumption of these products was the belief that medications or supplements improved the immune system $(88.38 \%)$. Other reasons included its ability to protect from fatigue $(6.61 \%)$, to reduce the disease symptoms (3.21\%), to support respondents' activity $(1.2 \%)$, and to kill SARS-CoV-2 (0.6\%) (Figure 2A, Table S5 I5-6). Unfortunately, more than two-thirds of the user conducted self-medication, without consulting health personnel (Figure 2B). They obtained the information about "anti-COVID" medications and supplements from friends/ relatives $(33.03 \%)$, news $(25.84 \%)$, and social media $(22.92 \%)$, followed by information provided in the product's brochures $(9.89 \%$, Figure $2 \mathrm{C})$. 
Table 2 Comparison of Medications and Supplements Consumption Between Housewives and Working Mothers

\begin{tabular}{|c|c|c|c|c|c|c|}
\hline & \multicolumn{2}{|c|}{ Housewives } & \multicolumn{2}{|c|}{ Working } & \multirow[t]{2}{*}{$\mathbf{Z}$} & \multirow[t]{2}{*}{$P$ value } \\
\hline & $\mathbf{N}$ & Mean \pm SD & $\mathbf{N}$ & Mean \pm SD & & \\
\hline \multicolumn{7}{|l|}{ Medications } \\
\hline $\begin{array}{l}\text { Not consumed } \\
\text { Not routinely consumed } \\
\text { Routinely consumed }\end{array}$ & $\begin{array}{l}184 \\
26 \\
10\end{array}$ & $\mathrm{I} .2 \mathrm{I} \pm 0.5 \mathrm{I}$ & $\begin{array}{l}337 \\
39 \\
14\end{array}$ & $1.17 \pm 0.46$ & -0.939 & 0.348 \\
\hline \multicolumn{7}{|l|}{ Vitamin/Minerals } \\
\hline $\begin{array}{l}\text { Not consumed } \\
\text { Not routinely consumed } \\
\text { Routinely consumed }\end{array}$ & $\begin{array}{l}60 \\
92 \\
68\end{array}$ & $2.04 \pm 0.76$ & $\begin{array}{l}62 \\
205 \\
123\end{array}$ & $2.16 \pm 0.67$ & -1.856 & 0.063 \\
\hline \multicolumn{7}{|l|}{ Herbs/Natural Products } \\
\hline $\begin{array}{l}\text { Not consumed } \\
\text { Not routinely consumed } \\
\text { Routinely consumed }\end{array}$ & $\begin{array}{l}41 \\
91 \\
88\end{array}$ & $2.21 \pm 0.74$ & $\begin{array}{l}144 \\
175 \\
71\end{array}$ & $1.82 \pm 0.72$ & -6.311 & 0.000 \\
\hline
\end{tabular}

Notes: Boldface $\mathrm{P}$ values indicate significant differences between two groups based on Kruskal-Wallis test. The frequency of medications/supplements were assessed $0=$ not consumed, $\mathrm{I}$ = not routinely consumed, and 3 = routinely consumed.

Furthermore, the association between sociodemographic factors and "anti-COVID" consumption behavior was analyzed in both groups. In the housewives, education influenced the respondent's "anti-COVID" medications and supplements consumption behavior, with respondents who graduated from high school more likely to consume "antiCOVID" medications. Meanwhile, in working mothers, consumption of medications was associated with age, family income, and family expenses. The younger and older working mothers more likely to consume vitamin and mineral supplementation compared to middle age groups. Respondents with higher income and have fewer family expenses more likely to consume supplementation such as vitamins, minerals, and also natural products compared to the other groups (Table S5 I7-8). Figure 2D and Table S4 showed the influence of sociodemographic factors on "antiCOVID" consumption behavior.

\section{Association Between Mental Health State and Consumption of "Anti-COVID" Medications and Supplements}

We found that among 128 respondents with depression, $65.6 \%$ consumed a combination of medications, vitamins/ minerals, and herbs/natural products during the pandemic. In contrast, $26.6 \%$ consumed single medications or supplements, and only $7.8 \%$ did not consume any "antiCOVID" products. Of the 156 respondents categorized with anxiety, $64.1 \%$ consumed a combination of medications and supplements to prevent SARS-CoV-2 infection; $25.6 \%$ consumed single medications or supplements, while only $10.3 \%$ of respondents did not consume any medications or supplements during the pandemic. Nevertheless, of the 50 respondents in the stress category, $66 \%$ consumed a combination of medications and supplements (vitamins, minerals, herbs, or natural products), $28 \%$ used single medications or supplements, and $6 \%$ did not consume any "anti-COVID" products (Figure S2).

To identify associations between the mental health status of mothers with school-age children and the consumption of "anti-COVID" medications and supplementation, a Fisher's Exact test was performed. The results indicated that there was no association between medications/supplements of "anti-COVID" consumption and mental health status in this study (Table 3).

\section{Discussion}

The increasing burden during this pandemic is undeniable, including for mothers with school-age children. ${ }^{11}$ Increasing incidences of child abuse and domestic violence were reported from various places worldwide. ${ }^{12-14}$ In the early pandemic, changes of activity and waves of false information increased fear; therefore, mothers try to prevent from getting infected by practicing selfmedication. ${ }^{30-32}$ The children's online learning increased their burden, especially for mothers with responsibilities 

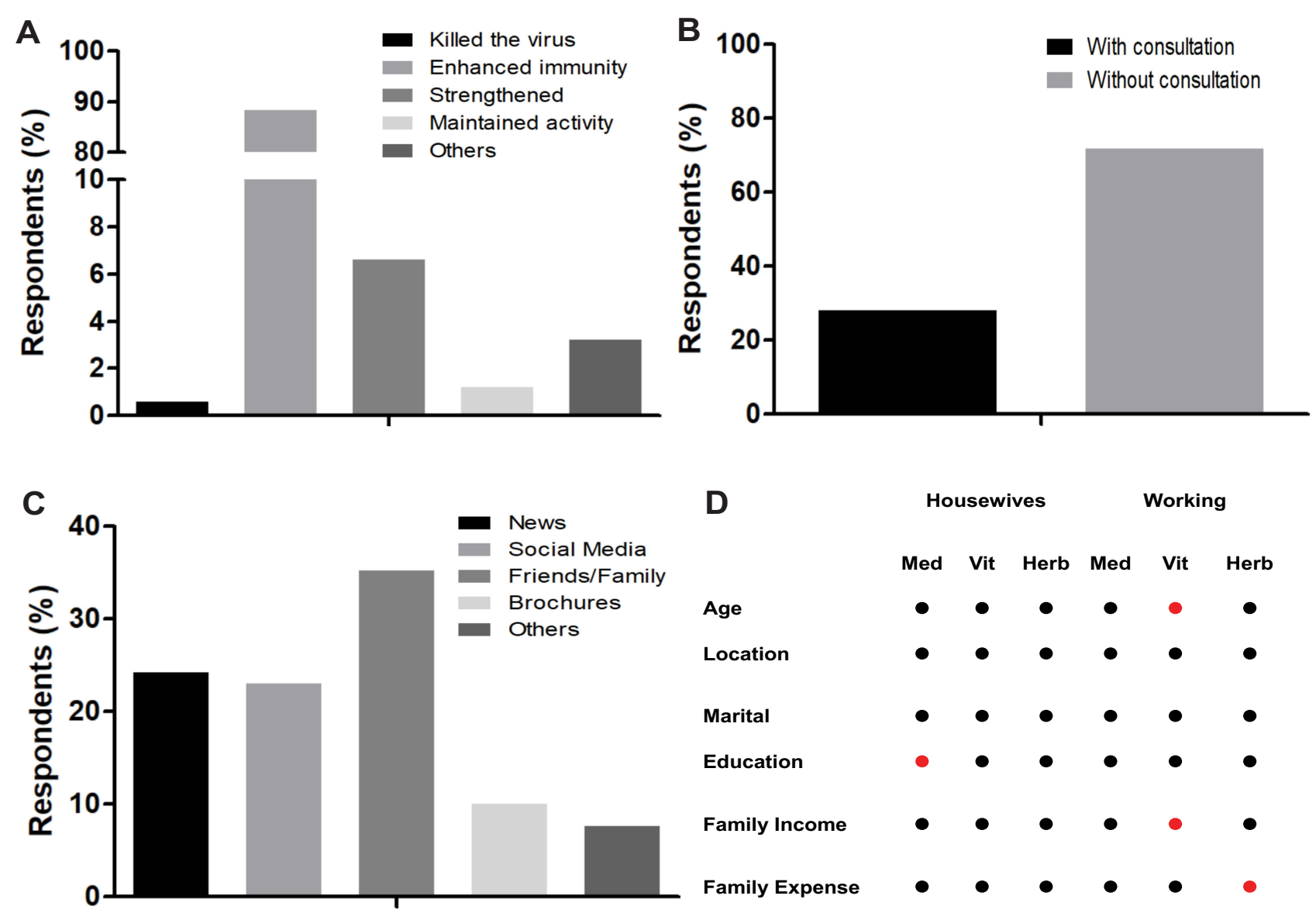

Figure 2 Reason, medical provider consultation, source of information, and sociodemographic effects on "anti-COVID" medications and supplementation consumption. (A) Reason for medications, vitamin/mineral supplementations, herbs/natural product supplementations of Indonesian mothers with school-age children. (B) Consultation with a health professional before consuming medications or supplementations. (C) Source of medications and supplements information. (D) Influences of sociodemographic factors on the "anti-COVID" consumption. Sociodemographic factors significantly $(\bullet)$ and non-significantly $(\bullet)$ influenced the "anti-COVID" intake analyzed by Kruskal Wallis Test. A complete statistical analysis was provided in Table S4.

such as nursing or working mothers. ${ }^{33}$ Our study in 610 Indonesian mothers with school-age children found that a quarter reported mental health problems such as depression $(21 \%)$, anxiety $(25.57 \%)$, and stress $(8.2 \%)$.

Interestingly, our study revealed higher scores on the DASS-21 were observed in housewives than working mothers; albeit after categorization into the level for each disorder, only incidence of depression, but not anxiety and stress, was higher in housewives than the working mothers during this pandemic. Our result supports the previous studies that conclude working mothers had better health, less depressive symptoms, and higher self-esteem compared to housewives. ${ }^{26,27}$ This finding differs from a study involving 8031 Indonesian citizens during 8 days

Table 3 Association Between Medications or Supplementations Consumption and Mental Health State in Indonesian Mother with School-Age Children

\begin{tabular}{|c|c|c|c|c|c|c|}
\hline & \multicolumn{2}{|l|}{ Medications } & \multicolumn{2}{|l|}{ Vitamins/Minerals } & \multicolumn{2}{|l|}{ Natural Products } \\
\hline & Fisher's Exact Value & $\mathbf{P}$ value & Fisher's Exact Value & $P$ value & Fisher's Exact Value & $P$ value \\
\hline Depression & 10.568 & 0.121 & 7.698 & 0.218 & 3.296 & 0.836 \\
\hline Anxiety & 11.690 & 0.114 & 4.290 & 0.842 & 8.699 & 0.348 \\
\hline Stress & 7.366 & 0.197 & 1.399 & 0.979 & 7.365 & 0.263 \\
\hline
\end{tabular}


of June 2020, which reported that females and working individuals were susceptible to have anxiety symptoms during this pandemic compared to the housewives. ${ }^{25}$ One important note was the previous study did not use a validated and standardized anxiety measurement.

Due to large-scale social restriction during this pandemic, the majority of the mother in both groups were staying at home; thus, the tendency toward mental health problems in housewives groups was not caused by staying at home but was primarily due to less appreciation, less self-actualization, and low self-esteem. ${ }^{27}$ A study in Iran and India found a similar result in a non-pandemic situation. ${ }^{34,35}$ The incidence was associated with the older age, less educated, and lower socioeconomic status. $^{35}$

Unfortunately, based on our qualitative study, most respondents with mental health problems did not find help from healthcare professionals, which might be caused by that negative stigma attached to mental health patients, ${ }^{36,37}$ even though telemedicine has been widely implemented during this pandemic. ${ }^{38}$ Lack of knowledge might contribute to this stigma, as a study in 1269 Indonesians showed a negative relationship between the knowledge on mental health diseases with the negative stigma to this condition. ${ }^{39}$ Therefore, a public education campaign to increase awareness of mental health problems is important, ${ }^{40}$ such as developing an online mental health supporting group and a mental health calculator as a screening tool during the pandemic. ${ }^{41}$

Our study found that age, marital status, and the balance between family income and expense influenced the mental health of mothers with school-age children during the pandemic. The older working mother more likely to have mental health issues since they were a vulnerable population to get infected by SARS-CoV-2 and to developed severe COVID-19. The younger working mother also more prone to have mental issues compared to middle age groups since they might have younger children that still need extra attention, ${ }^{42}$ while the work responsibility was also important. Our data were similar to several studies that found the older age more likely to develop depression or mental health issues. ${ }^{35,43}$

Another factor that might contribute to the incidence of anxiety was marital status, where the DASS- 21 score of unmarried/widower/divorce mother was significantly higher compared to the married mother. This finding is similar with 1612 twin pairs that found that married twin has lower depressive symptom compared to the unmarried twin. ${ }^{44}$ However, it is slightly differs with study in 1751 elder that found marriage men has lower depressive symptom, but not with marriage women. ${ }^{45}$

As expected, those with less income with more life expenses tended to have mental health issues, both in housewives and working mother groups. The relationship between poor mental health with low-income households has been extensively reported. ${ }^{46,47}$ Several mental health issues have been linked to low-income households, such as depression, anxiety, stress, and also suicide. Lack of nutrition, poor prenatal and birth outcomes, infection, environmental toxins might affect the development of several neurotransmitters ${ }^{48}$ and leads to disturbance of the hypothalamic-pituitary-adrenal axis which important in stress response. $^{49}$

Nevertheless, none of the respondents admitted that they had relationship problems with others because of their mental health status. However, it needs to be aware that individuals with poor mental health problems are susceptible to get an infection ${ }^{50}$ and to develop a physical illness due to their lifestyle and less likely to get standard treatment. ${ }^{51}$ Apparently, this population also tends to avoid the vaccination program which now has become available through national and international programs. $^{52,53}$

Adaptation is a human ability to survive, including during this pandemic. Disinformation regarding COVID19 treatment and prevention spread widely throughout the news, social media, and friend networks. ${ }^{55}$ This information included utilization of antimalarials, antibiotics, antivirals, vitamins, minerals, and herbal supplements. ${ }^{18,19}$ In Indonesia, these medications are readily available on e-commerce platforms without a prescription from healthcare professionals. ${ }^{54}$ This study showed that $55.4 \%(\mathrm{n}=$ 338 ) respondents consumed herbs or natural products during the pandemic, especially in the early stages. Since the benefit and the safety of routinely consume these products is still unclear, ${ }^{55}$ seeking advice from the healthcare professional is important. Unfortunately, our findings suggest that only a quarter of the respondents consulted with a healthcare professional before consuming the medications or supplements. The majority obtained information from family and friends, followed by social media, news, and product brochures. These practices are dangerous with possibilities to develop adverse reactions, drug-drug or drug-herb interactions, and resistance in antimicrobials as the clinical consequences. Social pharmacology and pharmacovigilance are essential to prevent these practices and 
identify the resulting cases. ${ }^{19}$ Moreover, by understanding the pattern of disinformation, countermeasures can be taken to prevent escalation of false information including on the vaccination program. Collaboration between government, journalists, scholars, and citizens are needed to combat the spreading of disinfodemics. ${ }^{56}$

This study showed no association between mental health status and "anti-COVID" medications/supplements usage. However, some studies demonstrate a correlation between mental disorders with substance abuse, ${ }^{57}$ as well as the effect of drugs that widely use as COVID-19 treatments, such as antimalarial and antiviral, on psychiatry disorders. ${ }^{58,59}$ Regrettably, our findings could not conclude how these two aspects interfere with each other. Albeit the application of an online questionnaire was very efficient, limited access to the respondents, unstable of internet, unfamiliarity with the internet, or residing in remote areas might cause bias in our data. Even though this pitfall was conquered by direct recruitment by trained surveyors, more respondents are necessary to draw complete pictures on mental health and medications/supplements consumption in Indonesia during this pandemic, especially in the vulnerable population such as mothers with school-age children.

\section{Conclusion}

This study showed the importance of controlling information and expanding the mother's knowledge to find the correct information to minimize the unwanted effect in the post COVID-19 pandemic. Disinformation regarding "anti-COVID" treatments and prevention widely spread, contributing to the consumption of medications and supplements leads to irrational self-medication practice. Collaborative measurement to prevent the escalation of new clinical consequences and medical problems due to this practice is necessary. Increasing awareness of mental health issues in the community, especially in the vulnerable population such as mother with school-age children, is necessary to avoid detrimental effects that might occur in the future.

\section{Acknowledgment}

We would like to thank Nurina Hasanatuludhhiyah, MD for valuable comments and suggestions.

\section{Funding}

This study was funded by the RKAT the Institute of Research and Innovation (LPI) Universitas Airlangga No. 1082/UN3.14/PT/2020.

\section{Disclosure}

The authors report no conflicts of interest in this work.

\section{References}

1. Dawood FS, Ricks P, Njie GJ, et al. Observations of the global epidemiology of COVID-19 from the prepandemic period using web-based surveillance: a cross-sectional analysis. Lancet Infect Dis. 2020;20(11):1255-1262. doi:10.1016/S1473-3099(20) 30581-8

2. Cauchemez S, Kiem CT, Paireau J, Rolland P, Fontanet A. Lockdown impact on COVID-19 epidemics in regions across metropolitan France. Lancet. 2020;396(10257):1068-106910.

3. Depellegrin D, Bastianini M, Fadini A, Menegon S. The effects of COVID-19 induced lockdown measures on maritime settings of a coastal region. Sci Total Environ. 2020;740:140123. doi:10.1016/j. scitotenv.2020.140123

4. Burki T. Mass testing for COVID-19. Lancet Microbe. 2020;1(8): e31710.

5. Lopes-Júnior LC, Bomfim E, Silveira DSCD, Pessanha RM, Schuab SIPC, Lima RAG. Effectiveness of mass testing for control of COVID-19: a systematic review protocol. BMJ Open. 2020;10(8): e040413-e040413. doi:10.1136/bmjopen-2020-040413

6. Schraff D. Political trust during the Covid-19 pandemic: rally around the flag or lockdown effects? Eur J Polit Res. 2020. doi:10.1111/ 1475-6765.12425

7. Allard T, Lamb K. Endless first wave: how Indonesia failed to control coronavirus. Reuters. 2020; 2020: Healthcare \& pharma.

8. Djalante R, Lassa J, Setiamarga D, et al. Review and analysis of current responses to COVID-19 in Indonesia: period of January to March 2020. Progress Disaster Sci. 2020;6:100091. doi:10.1016/j. pdisas.2020.100091.

9. Pandey D, Bansal S, Goyal S, et al. Psychological impact of mass quarantine on population during pandemics-The COVID-19 LockDown (COLD) study. PLoS One. 2020;15(10):e240501. doi:10.1371/journal.pone.0240501.

10. Singh S, Roy D, Sinha K, Parveen S, Sharma G, Joshi G. Impact of COVID-19 and lockdown on mental health of children and adolescents: a narrative review with recommendations. Psychiatry Res. 2020;293:113429. doi:10.1016/j.psychres.2020.113429

11. Janssen LHC, Kullberg M-LJ, Verkuil B, et al. Does the COVID-19 pandemic impact parents' and adolescents' well-being? An EMAstudy on daily affect and parenting. PLoS One. 2020;15(10): e0240962. doi:10.1371/journal.pone.0240962

12. Zhang H. The Influence of the Ongoing COVID-19 Pandemic on Family Violence in China. J Fam Violence. 2020;1-11. doi:10.1007/ s10896-020-00196-8

13. Usher K, Bhullar N, Durkin J, Gyamfi N, Jackson D. Family violence and COVID-19: increased vulnerability and reduced options for support. Int J Ment Health Nurs. 2020;29(4):549-552. doi:10.1111/ inm. 12735

14. Sharma A, Borah SB. Covid-19 and Domestic Violence: an Indirect Path to Social and Economic Crisis. J Fam Violence. 2020. doi:10.1007/s10896-020-00188-8

15. Lenzen M, Li M, Malik A, et al. Global socio-economic losses and environmental gains from the Coronavirus pandemic. PLoS One. 2020;15(7):e0235654. doi:10.1371/journal.pone.0235654

16. Pfefferbaum B, North CS. Mental Health and the Covid-19 Pandemic. New Engl J Med. 2020;383(6):510-512. doi:10.1056/ NEJMp2008017

17. Ren S-Y, Gao R-D, Chen Y-L. Fear can be more harmful than the severe acute respiratory syndrome coronavirus 2 in controlling the corona virus disease 2019 epidemic. World J Clin Cases. 2020;8 (4):652-65710. doi:10.12998/wjcc.v8.i4.652 
18. Islam MS, Sarkar T, Khan SH, et al. COVID-19-Related Infodemic and Its Impact on Public Health: a Global Social Media Analysis. Am J Trop Med Hyg. 2020;103(4):1621-1629. doi:10.4269/ajtmh.200812

19. Tuccori M, Convertino I, Ferraro S, et al. The Impact of the COVID19 "Infodemic" on Drug-Utilization Behaviors: implications for Pharmacovigilance. Drug Safety. 2020;43(8):699-709. doi:10.1007/ s40264-020-00965-w

20. Kimura S, Nakamura Y. A Case Study in Indonesia: self-medication and Limited Access. In: Poor Quality Pharmaceuticals in Global Public Health. Singapore: Springer Singapore; 2020:119-147.

21. d'Arqom A, Nasution Z. Herbal medicine perception and practice among childbearing mother with medical education background in bandung: a preliminary study. Maj Obat Trad.2015;19(2):410.

22. Atmadani RN, Nkoka O, Yunita SL, Chen Y-H. Self-medication and knowledge among pregnant women attending primary healthcare services in Malang, Indonesia: a cross-sectional study. $B M C$ Pregnancy Childbirth. 2020;20(1):42. doi:10.1186/s12884-0202736-2

23. Arjadi R, Nauta MH, Scholte WF, et al. Guided Act and Feel Indonesia (GAF-ID) - Internet-based behavioral activation intervention for depression in Indonesia: study protocol for a randomized controlled trial. Trials. 2016;17(1):455. doi:10.1186/s13063-016$1577-9$

24. World Health Organisation. Mental Health ATLAS 2017 Member State Profile. World Health Organisation; 2020. Available from: https://www.who.int/mental_health/evidence/atlas/profiles-2017/IDN. pdf?ua=1. Accessed June 4, 2020.

25. Megatsari H, Laksono AD, Ibad M, et al. The community psychosocial burden during the COVID-19 pandemic in Indonesia. Heliyon. 2020;6(10). doi:10.1016/j.heliyon.2020.e05136.

26. Buehler C, O'Brien M. Mothers' part-time employment: associations with mother and family well-being. J Fam Psychol. 2011;25 (6):895-906. doi:10.1037/a0025993

27. Melissa E, Hamidati A, Saraswati MS, Flor A. The Internet and Indonesian Women Entrepreneurs: examining the Impact of Social Media on Women Empowerment. In: Chib A, May J, Barrantes R, editors. Impact of Information Society Research in the Global South. Singapore: Springer Singapore; 2015:203-222.

28. Eysenbach G. Improving the quality of Web surveys: the Checklist for Reporting Results of Internet E-Surveys (CHERRIES). $J$ Med Internet Res. 2004;6(3):e34-e3410. doi:10.2196/jmir.6.3.e34

29. Lovibond SH, Lovibond PF, eds. Manual for the Depression Anxiety Stress Scales. 2nd ed. Sydney: sychology Foundation; 1995.

30. Hamulka J, Jeruszka-Bielak M, Górnicka M, Drywień ME, Zielinska-Pukos MA. Dietary Supplements during COVID-19 Outbreak. Results of Google Trends Analysis Supported by PLifeCOVID-19 Online Studies. Nutrients. 2020;13(1). doi: $10.3390 /$ nu 13010054

31. Sadio AJ, Gbeasor-Komlanvi FA, Konu RY, et al. Assessment of self-medication practices in the context of the COVID-19 outbreak in Togo. BMC Public Health. 2021;21(1):58. doi:10.1186/s12889-02010145-1

32. Quispe-Cañari JF, Fidel-Rosales E, Manrique D, et al. Selfmedication practices during the COVID-19 pandemic among the adult population in Peru: a cross-sectional survey. Saudi Pharm J. 2021;29(1):1-11. doi:10.1016/j.jsps.2020.12.001

33. Dong C, Cao S, Li H. Young children's online learning during COVID-19 pandemic: chinese parents' beliefs and attitudes. Child Youth Serv Rev. 2020;118:105440. doi:10.1016/j. childyouth.2020.105440

34. Saravi FK, Navidian A, Rigi SN, Montazeri A. Comparing health-related quality of life of employed women and housewives: a cross sectional study from southeast Iran. BMC Women's Health. 2012;12(1):41. doi:10.1186/1472-6874-12-41
35. Urvashi U, Girdhar S, Chaudhary A, Gupta S, Monga S. Sociodemographic co-relates of depression among housewives in rural area of district Ludhiana. Int $J$ Community Med Public Health. 2019;6(5):510.

36. Henderson C, Evans-Lacko S, Thornicroft G. Mental illness stigma, help seeking, and public health programs. Am J Public Health. 2013;103(5):777-780. doi:10.2105/AJPH.2012.301056

37. Knaak S, Mantler E, Szeto A. Mental illness-related stigma in healthcare: barriers to access and care and evidence-based solutions. Healthc Manage Forum. 2017;30(2):111-116. doi:10.1177/ 0840470416679413

38. Bashshur RL, Shannon GW, Bashshur N, Yellowlees PM. The Empirical Evidence for Telemedicine Interventions in Mental Disorders. Telemed J E Health. 2016;22(2):87-113. doi:10.1089/ tmj.2015.0206

39. Hartini N, Fardana NA, Ariana AD, Wardana ND. Stigma toward people with mental health problems in Indonesia. Psychol Res Behav Manag. 2018;11:535-541. doi:10.2147/PRBM.S175251

40. Zhou X, Snoswell CL, Harding LE, et al. The Role of Telehealth in Reducing the Mental Health Burden from COVID-19. Telemed e-Health. 2020;26(4):377-379. doi:10.1089/tmj.2020.0068

41. d'Arqom A, Sawitri B, Nasution Z, et al. Development of online mental health supporting group to reduce mental burden during Covid-19 Pandemic. J Public Serv. 2020;4(2). doi:10.20473/jlm. v4i2.2020.251-258

42. Agnafors S, Bladh M, Svedin CG, Sydsjö G. Mental health in young mothers, single mothers and their children. BMC Psychiatry. 2019;19 (1):112. doi:10.1186/s12888-019-2082-y

43. Frech A, Damaske S. The relationships between mothers' work pathways and physical and mental health. J Health Soc Behav. 2012;53 (4):396-412. doi:10.1177/0022146512453929

44. Beam CR, Dinescu D, Emery R, Turkheimer E, Twin A. Study on Perceived Stress, Depressive Symptoms, and Marriage. J Health Soc Behav. 2017;58(1):37-53. doi:10.1177/0022146516688242

45. St John PD, Montgomery PR. Marital status, partner satisfaction, and depressive symptoms in older men and women. Can J Psychiatry. 2009;54(7):487-492. doi:10.1177/070674370905400710

46. Hodgkinson S, Godoy L, Beers LS, Lewin A. Improving Mental Health Access for Low-Income Children and Families in the Primary Care Setting. Pediatrics. 2017;139(1):e2015117510. doi:10.1542/peds.2015-1175

47. Sareen J, Afifi TO, McMillan KA, Asmundson GJG. Relationship between household income and mental disorders: findings from a population-based longitudinal study. Arch Gen Psychiatry. 2011;68 (4):419-427. doi:10.1001/archgenpsychiatry.2011.15

48. Cusick SE, Georgieff MK. The Role of Nutrition in Brain Development: the Golden Opportunity of the "First 1000 Days". J Pediatr. 2016;175:16-21. doi:10.1016/j.jpeds.2016.05.013

49. Smith SM, Vale WW. The role of the hypothalamic-pituitary-adrenal axis in neuroendocrine responses to stress. Dialogues Clin Neurosci. 2006;8(4):383-395. doi:10.31887/DCNS.2006.8.4/ssmith

50. Lee SW, Yang JM, Moon SY, et al. Association between mental illness and COVID-19 susceptibility and clinical outcomes in South Korea: a nationwide cohort study. Lancet Psychiatry. 2020;7 (12):1025-103110.

51. De Hert M, Correll CU, Bobes J, et al. Physical illness in patients with severe mental disorders. I. Prevalence, impact of medications and disparities in health care. World Psychiatry. 2011;10(1):52-77. doi:10.1002/j.2051-5545.2011.tb00014.x

52. Kontoangelos K, Economou M, Papageorgiou C. Mental Health Effects of COVID-19 Pandemia: a Review of Clinical and Psychological Traits. Psychiatry Investig. 2020;17(6):491-505. doi:10.30773/pi.2020.0161

53. Grimes DR. Medical disinformation and the unviable nature of COVID-19 conspiracy theories. PLoS One. 2021;16(3):e0245900. doi:10.1371/journal.pone. 0245900 
54. kumparanNEWS. BPOM Temukan 2.645 Penjual Online yang Klaim Jual Obat Anti-Corona. kumparanNEWS. 2020

55. Ekor M. The growing use of herbal medicines: issues relating to adverse reactions and challenges in monitoring safety. Front Pharmacol. 2014;4:177. doi:10.3389/fphar.2013.00177

56. Chen K, Luo Y, Hu A, Zhao J, Zhang L. Characteristics of Misinformation Spreading on Social Media During the COVID-19 Outbreak in China: a Descriptive Analysis. Risk Manag Healthc Policy. 2021;14:1869-1879. doi:10.2147/rmhp.S312327

57. Chiappini S, Guirguis A, John A, Corkery JM, Schifano F. COVID19: the Hidden Impact on Mental Health and Drug Addiction. Front Psychiatry. 2020;11:767. doi:10.3389/fpsyt.2020.00767
58. García CAC, Sánchez EBA, Huerta DH, Gómez-Arnau J. Covid-19 treatment-induced neuropsychiatric adverse effects. Gen Hosp Psychiatry. 2020;67:163-164. doi:10.1016/j.genhosppsych. 2020.06.001

59. Zhang K, Zhou X, Liu H, Hashimoto K. Treatment concerns for psychiatric symptoms in patients with COVID-19 with or without psychiatric disorders. Br J Psychiatry. 2020;217(1):351. doi:10.1192/ bjp.2020.84

\section{Publish your work in this journal}

The International Journal of Women's Health is an international, peerreviewed open-access journal publishing original research, reports, editorials, reviews and commentaries on all aspects of women's healthcare including gynecology, obstetrics, and breast cancer. The manuscript management system is completely online and includes a very quick and fair peer-review system, which is all easy to use. Visit http://www.dovepress.com/testimonials.php to read real quotes from published authors. 